\title{
Strategy to Build Smart City: \\ Form of Public Service Innovative and Sustainable
}

\author{
Djoko Poernomo \\ Faculty of Social and Political Sciences \\ Jember University
}

\begin{abstract}
The population of the city is growing. Therefore the city authorities are required to provide quality public services, fast, accurate, and inexpensive. Solutions to provide excellent public services is to build a smart city that can serve all the needs of the public as well. The purpose of this paper is to uncover a strategy to build an innovative smart city, which can assure of services to meet all the needs of the public, both economic and non-economic sustainable manner, by learning from the various theories as well as the success story of a smart city. The results showed that, there needs to be a comprehensive analysis in order to develop a strategy that is integrated and complete to build a smart city that is able to realize innovative public services and sustainable.
\end{abstract}

Keywords--Strategy, smart city, public service, innovative, sustainable

\section{A. Background}

\section{INTRODUCTION}

Public services in every city now more complex and complicated as the number of population increases and the level of education and knowledge of the population are getting better. There is a tendency the higher the level of education and knowledge of the community, the higher the demands on public services. Public services may involve variations of the service, its range, and quality. Public services such as providing shelter, roads, education, electricity, hospitals, water, markets, entertainment venues, transportation, orphanages, green parks, jobs, security, quiet and comfortable stay in the city, work and much more. Therefore, the city government should be able to provide a public service that is fast, precise, multi-sector, high quality, effective, yet efficient. Thus, the mouth of the public service only one that embodies the quality of life is better than before.

For those municipalities not easy to provide public services that are innovative, satisfying, comprehensive, and sustainable. This is due, public services that have four features should be integrated into the strategy of building the city of dreams, which is better known as the smart city. This is not a new concept but it remains a discussion of interest to academics, bureaucracy, consultants, practitioners, and the public until now. The concept of smart city has become "iconic" city development today. Smart city is an expression of a dream city to be able to accommodate all the needs of the population, both in the context of the economic / business and non-economic. Interpretation smart city very much. Nevertheless, Nam \& Pardo (2012) were able to map the elements of smart city that is technology, people, and the community. Therefore, it is natural that there is a call as a digital city, city information, knowledge city, smart community and others. Whatever the appellation concept and its elements, there appears similar thoughts from experts in realizing the smart city based on information and communication technology (information communication technologies / ICTs). The author agrees with it (ICTs) but slightly different in the smart city-forming element.

Smart city embodies a visionary approach is needed. In addition, building a smart city requires strategic thinking, creative, innovative, holistic, and is supported by the acquisition of knowledge sufficient to reach good governance to municipalities in preparing smart city. Conducted a planned strategic means for the sake of the present and the future, ranging from the identification of public service needs are very varied, grouping needs, the process of integration and abstraction, fulfillment solutions, and implementation. Creative means the ability to produce a useful and new plans at the level of individuals, organizations, and communities. Innovative means no tools or new processes that benefit individuals, organizations, and communities. Holistic means all that is planned to start at the strategic level to the work program is integrated into a system.

It all indicates the construction of smart city will be more effective if the government of the city using a strategic management framework that puts people and the natural environment as a major factor. Without it, the city government will not be able to provide a satisfactory public services and sustainable while maintaining the damage of the natural environment. From previous research findings as well as the implementation of the concept of smart city in various cities of the world there has actually been significant progress towards improvement of the quality of people's living standards. However, with the persistence of flooding, deforestation, landslides, resulting in the suffering of the people and their demonstrations, complaints of people in different parts of the cities of the world (including Indonesia) expressed public dissatisfaction with the services provided by the city government is still a lot going on. That is the interest the authors to write this paper by adding new elements forming smart city using a strategic management perspective.

\section{B. Problems}

Based on the above description, the problem formulation of this paper is how a strategic move to build an innovative smart city as a form of public service that provides a comprehensive, satisfactory and sustainable while maintaining the damage of the natural environment?

\section{Objectives}

The purpose of writing this paper is to discuss strategic move to build an innovative smart city in the perspective of strategic management which guarantees public services will be comprehensive, satisfying, and sustainable while maintaining the damage of the natural environment. 


\section{II.LITERATURE}

\section{A. Smart City}

In essence, humans are the heart of life, as well as the natural environment. Both are the gift of God that must be considered (served) because its existence as a core factor of life that does not happen suffering and damage. Outside it is a contributing factor in providing services eg city government, technology, and infrastructure.

The essence of the city government is to provide the best services to the population while maintaining the integrity of the natural environment is not damaged. Perhaps what is different is the way the management of public services performed by the city government. For example, if the city government bureaucracy as the main actor and the place people or vice versa is not a major factor. So in theory the old paradigm of public administration are public administration, new public management, and the new public service. Smart city development would be more appropriate when using new perspective of public service. People who should be the main focus of service to safeguard the natural environment, then the other.

Basically the concept of multi-interpretative smart city. The term smart that causes intelligent interpretation of urban development be varied. Yahya (2013) for example, smart interpret as being (though flavor), thinking (though the ratio) and act smart (though the action) in the work. So smart then interpreted as the presence of sharp intuition, creative and innovative and impressive acts. Schuurman et al., 2012: Robertas \& Giedrus, 2014: Dameri et al., 2014. interpret the smart city as digital cities, intelligent cities, and ubiquitous cities. South Korea, translating smart city as a city of "knowledge," the city "digital", the city of "cyber" or city "eco" as well. Here are some definitions of smart city (Schuurman et al., 2012).

"The uses of smart computing technologies to make the official infrastructure component and services of a city which include city administration, education, healthcare, public safety, real estate, transportation, and utilities- more intelligent, interconnected, efficient". "A city well performing in a forward-looking way in economy, people, governance, mobility, environment, and living, built on the smart combination endowments and activities of self-decisive, independent and aware citizens". "A city striving to make it self 'smarter' (more efficient, sustainable, equitable, and livable)". "A city that monitor and integrates conditions of all of critical infrastrutures, including roads, bridges, tunnels, rails, subways, airport, seaports, communications, water, power, even major building, can better optimize its resources, plan its preventive maintenance activities, and monitor security aspect while maximizing service to its citizens". "An instrumented, interconnected, and intelligent city. Instrumentations enables the capture and integration of realworld data throught the use of sensors, kiosk, meters, personal devices, appliances, cameras, smartphone, implanted medical devices, the web, and other similar data-acquisition system, including social networks as networks of human sensors. Interconnected means the integration of those data into an enterprise computing platform and the communication of such information among the various city services. Intelligent refers to the inclusion of complex analytic, modeling, optimization, and visualization in the operational business processes to make better operational decisions". "A city that give inspiration, share culture, knowledge, and life, a city that motivates its inhabitants to create and flourish in their own lives". "A city where the ICT strengthen the freedom of speech and the accessibility to public information and services".

On the other hand, according to the Department for Business Innovation \& Skills (2013) there are five very important aspects to be used as an approach in building the city of dreams, namely:

a modern digital infrastructure, combined with a secure but open access approach to public reuseable data, which enables citizens to access the information they need, when they need it;

a recognition that service delivery is improved by being citizen centric:this involves placing the citizen's needs at the forefront, sharing management information to provide a coherent service, rather than operating in a multiplicity of service silos (for example, sharing changes of address more effectively), and offering internet service delivery where possible (at a fraction of the face to face cost);

an intelligent physical infrastructure ("smart" systems or the Internet of Things), to enable service providers to use the full range of data both to manage service delivery on a daily basis and to inform strategic investment in the city/community (for example, gathering and analysing data on whether public transport is adequate to cope with rush hour peaks);

an openness to learn from others and experiment with new approaches and new business models; and

- transparency of outcomes/performance, for example, city service dashboards to enable citizens to compare and challenge performance, establishment by establishment, and borough by borough.

Whatever interpretation is given, the essence of smart city that should not be lost is the improvement or development of the city is done in a sustainable manner, taking into account functional aspects, structural, cultural, and aesthetic, through the use of information and communication technology as a base infrastructure services. Functional aspects, the construction of smart city should be able to accommodate people with their respective functions, whether as economic actors or businesses, social actors, these officials, who can work quietly, safely, and comfortably supported by infrastructure (roads, highways railways, bridges, ports, airports, banking, information technology, etc.). Structural aspects, construction of smart city should be able to guarantee the institutional and institutional systems running smoothly, both in terms of economics / business, social, and governance. Cultural aspects, the construction of smart city needs to consider the value of existing systems and develop in society. The aesthetic aspect, the construction of smart city approach is designed with eco-friendly nature, friendly people, technology friendly, hospitable governance, morality friendly. In short, smart city should be able to create a population on 
the move, doing so with a quiet, safe, comfortable, happy, and happy to stay in it.

\section{B. Strategic Management}

The simplest definition of strategy is action plans. The general definition strategy that is complete is a plan that is comprehensive, systematic, integrated into a single system, which connects the power of the organization to the outside environment (society), which is in the relationship, all received benefits, both economic benefits and non-economic so that the quality of life for the better than ever while maintaining the natural environment is not damaged. Elements of the strategy consists of (i) plans, (ii) integration, (iii) connecting the internal-external, and (iv) is useful. Terms of good strategy: (i) effective to solve the problem (the need), (ii) practical in the sense could be implemented in the existing situation by using the resources of the organization, (iii) feasible in reasionable time frame, (iv) cost effective and acceptable to stakeholders, and (v) pay attention to the appropriateness (fits) between resources and competencies with opportunities to meet the needs and fits between risk and expectations (Sampurno, 2011). The strategy therefore, needs to be managed professionally.

Nugraha (2014), the management strategy is defined as the art and science to formulate, implement, and assess the decisions which cross-functional that enable an organization achieve its objectives. Suyanto (2007), the management strategy is a set of decisions and actions designed to achieve the goals or objectives of the organization. Hit et al., (2005), strategic management as a series of managerial decisions and actions that determine the performance of the organization in the long term include environmental scanning, strategy formulation, strategy implementation, and evaluation and control.

Based on the above understanding, it can be concluded that the strategic management emphasis on observation and evaluation of the opportunities and threats of the external environment in terms of strengths and weaknesses of the organization, which is better known as a SWOT analysis (strengtheness, weaknessess, opportunities, and threats). Outputs from SWOT analysis is a strategic advantage profile, the basis for preparing the next strategic steps. According to Hunger \& Wheelen (1996), the next steps is to develop a vision, mission, goals, strategies, policies, programs, budgets, procedures, and ends with a measure of performance.

\section{DISCUSSION}

\section{A. Environmental Assessment External and internal}

External environmental factors are elements that are outside the organization municipality. Essential elements of the external environment assessed are as follows.

$$
\text { a. community }
$$

Society needs to be divided into groups that are more specific so relatively easily identified needs in order to prepare for its services. For example i) the industrial society (big industry, secondary industry, small industry): ii) higher income groups, medium, medium, low; iii) the total population in terms of gender, age structure; iv) and others.

$$
\text { b. Natural and geographical environment }
$$

Smart city development must take into account geographical circumstances and nature. The illustrations, in the city center where there are rivers, forests, fields, then as much as possible maintained existence and sustainability. It's certainly a formidable challenge to not displace rivers, forests, and fields. However, the government requires the construction of smart city smart city with a glorious breakthroughs so as not to sacrifice the natural environment or geographical conditions.

\section{c. Technology}

Rapid technological developments. The city authorities need to be extra careful in deciding the use of technology that ensures all community needs could be served. In this context, a comparative study on cities that have successfully implemented the technology as the infrastructure of public services, such as South Korea to the application of the "free wi fi".

\section{d. Infrastructure}

In this context, public service infrastructure needs to be evaluated. This evaluation is to obtain certainty what things that did not exist, that there is improved quality. Examples can be seen at page previous infrastructure.

Elements of the internal environment is everything that is owned by the city government organizations. Such elements include the following.

\section{a. Structure}

The organizational structure of smart city needs to be flexible so it easily adaptable to changing demands of public service. Their public complaints immediately got a response and quick solution. The organizational structure is appropriate for this case is the organic structure. Therefore, it is also necessary to note the placement of people with expertise, skills and knowledge sufficient to occupy the parts of the structure.

b. Culture

Culture is how to think, how to behave, how to make decisions, and how to behave or act in everyday. Culture is needed in the construction of smart city and is considered the natural environment as the main factors that are very worthy of attention, the utilization of information and communication technology as the basis of public service infrastructure in addition to other infrastructure such as roads, etc., and making the city very competitive.

\section{c. Resource}

Resources are all assets owned by the organization, can be intangible resources (eg intellectual capital) and tangible resources (eg roads, railways, ports, and airports). All of these resources need to be managed and deployed to realize the construction of smart city.

\section{$B$. The Importance of Vision and Mission}

Vision is a view far into the future of the organization, the organization's goals, and what should be done to achieve these objectives (Dirgantoro, 2004). Vision is loaded with philosophical values that need to be translated into values of strategic and concrete. Building a smart city desperately needed a strong and clear vision of the city government. Vision is ideal to be realized at a certain future. Vision build a smart city should be able to integrate the values

of economics / business, social, governmental, and other values. Therefore, the vision must be clear and focused. Not easy to build a vision for necessary dreamy, predict, estimate and analyze the many factors to consider so many years into the future. Consequently, the acquisition of knowledge 
(especially tacit knowledge) is enough for the city government is needed to build a proper vision. City of dreams as to what would be realized by the city authorities already exist in the minds of the city administration. Examples of smart city vision of London Canada in 2015-2019 is "A leader in commerce, culture, and innovation - our region's connections to the world", which can be interpreted as being a leader in trade, culture, and innovation in the world.

Vision organization / smart city needs to be derived on a mission. The organization's mission is basically to explain the uses and reasons why an organization exists. Purnomo and Zulkieflimansyah (2005), the mission of the organization must exist because it is the raison d'tre of the organization. They expressed the benefits of the organization's mission as follows: (i) help to focus resources in general, (ii) to help ensure that the organization is not involved in a conflict of interest, (iii) serve as the basis of thought common to allocate organizational resources, (iv) forming region extensive job responsibilities within the organization, and (v) serves as the basis for the development of the organization's goals. Thus, the mission is a statement of the reasons why the organization exists.

The mission of communicating to the public about smart city and its operations. Mission smart city can be prepared with a range of broad or narrow. Example missions London Canada 2015-2019 year is "At your service - a respected and inspired public service, building a better city for all" and then fitted with a values system: "individual responsibility, collective accountability, collaboration, and innovation". That is the guideline for the strategic planning of London Canada 2015-2019.

\section{Objective Formulation}

Smart city formulated objectives derived from the organization's mission. Lajimnya define what the organization's goals will be realized, when it will be done, and what measures of success. Objectives can be formulated into long-term goals, medium term and short term. Long-term goals can be up to 20 years ahead, the medium-term to 5 years to 10 years, and short-term goals can be resized one year. The destination can be more than one, and are arranged in statements. Preferably, the formulation for purposes other than in the form of qualitative statements are also accompanied by quantitative measures to be easily measured its performance in the future (eg within one year).

\section{Strategy Formulation}

Strategy is a plan of action to realize the objectives of the organization (smart city). The city government can formulate a strategy to optimize all resources to realize the power of a number of short-term goals have been set. If the short-term goals successfully realized, the strategy is directed to the medium-term objectives, so the pattern of effective strategic thinking. Strategy formulation should be supple or flexible in order to facilitate making adjustments if their demands so require. Suppose the demand of the people to preserve the natural environment or information technology findings that "forces" the city government to adjust itself in providing public services.

Examples of building smart city, a strategic focus area of London Canada 2015-2019 directed to strengthening our community, our growing economy, leading in public service, building a sustainable. The strength of the population relies on (i) a vibrant, connected, and engaged neighborhoods; (ii) diverse, inclusive, and welcoming community; (iii) caring and compassionate service; (iv) amazing arts, culture, and recreation experiences. Economic growth has relied on (i) a diverse and resilient economy; (ii) urban regeneration; (iii) local, regional, and global innovation; (iv) strategic, collaborative partnerships; (v) diverse employment opportunities. Leading in public service rests on (i) open, accountability, and responsive government; (ii) innovative and supportive organizational practices; (iii) proactive financial management; (iv) collaborative, engaged leadership; (v) excellent service delivery. Building a sustainable city rests on (i) a robust infrastructure; (ii) convenient and connected mobility choices; (iii) strong and healthy environment; (iv) beautiful places and spaces; (v) responsible growth; (vi) heritage conservation. Then each formulated its strategy by focusing on two questions: (i) what should be done? and (ii) how to do? Then described in more detail to a number of items on both questions. The illustration shows that all must be done carefully, accurately and comprehensively.

\section{E. Formulation of programs}

Policies in essence can be interpreted as a guideline for action. The formulation of the strategy that has been designed to be followed by policies that are directly related to the implementation of the strategy to be effective. In addition, it should be equipped with programming. The program is the charge of a number of activities that are concrete, detailed, and specific which is a derivation of the strategy. Contained in the program of activities, the allocated resources (human, expertise or skill, time started to work and finish the work, the cost of the necessary and desired performance targets).

\section{$F$. Assessment of performance}

Implementation of the strategy to build smart city must be measurable success. Size can be quantitatively and qualitatively. Both measures should be used because it could be there are things that can not be measured using quantitative measures. The measurement results can then be used as feedback to the smart city development goals, whether it has been achieved or not to follow up measures. The picture below is a model approach to strategic management in the construction of smart city. 


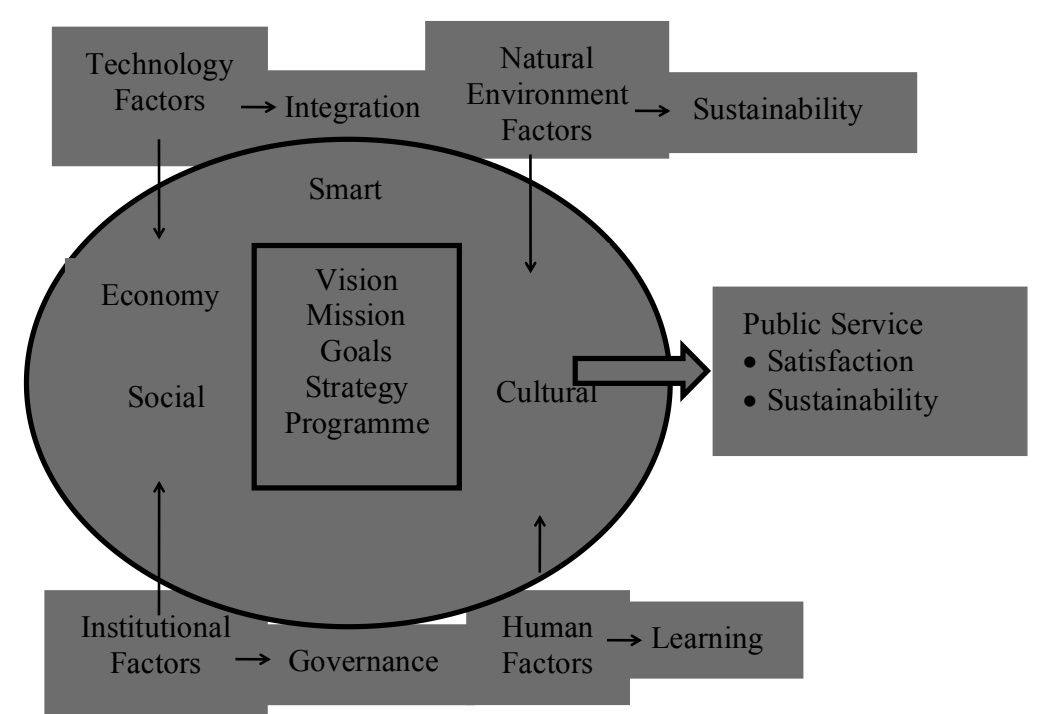

Figure 1. Strategic management approach in building a smart city (modification from Nam \& Pardo, 2011)

\section{CONCLUSION}

\section{A. Conclusions}

The conclusion of this paper is to (i) build the smart city requires a comprehensive approach that integrates into a single unit (system) with one ultimate goal, which caters to all the needs of the public with prompt, friendly, and satisfying, with the rest on the utilization information communication technology to the fullest and keep the damage of the environment (nature); (ii) utilization management concept in building a smart city strategy gives very clear guidelines on strategic measures so that everything will be identified from the obvious anyway. This causes the level of success of building a smart city that can satisfy sustainable society is huge.

\section{B. Recommendations}

Building a smart city is not easy because the city is multifunctional. Therefore, the proposed recommendations are (i) the required knowledge sufficient to municipalities, especially knowledge about the concept of management strategy, (ii) to develop a strategic plan to build smart city, elements of the natural environment should receive equal attention as elements more.

\section{BIBLIOGRAPHY}

[1] Damari, Renata Paola; Ricciardi, Francesca; D'Auria, Beatrice., 2014, Knowledge and Intellectual Capital in Smart City, European Conference on Knowledge Management 1: 250-257, ProQuest, download.

[2] Dirgantoro, Crown, 2004, Strategic Management, Jakarta, Published by Gramedia Widiasarana Indonesia.

[3] Hit, M.A., R.D, Ireland \& Robert E. Hoskisson, 2005, Strategic Management, USA, South-Western, Thomson Corporation.

[4] Hunger, J. David; Wheelen, Thomas L., 1996, Strategic Management, Published by Addison-Wesley Publishing Company.

[5] Jucevicius, Robertas; Jucevicius, Giedrus, 2014, From Knowledge to Smart City: A Conceptual Study, European Conference on Knowledge Management 2: 508-515, ProQuest, download.

[6] Schilling, Mellisa A., 2013, Strategic Management of Technological Innovation, Published by The Mc-Graw Hill Companies Inc.

[7] Nugraha, M. Quadrat, 2014, Manajemen Strategis Pemerintahan, cetakan ketiga, Jakarta, Penerbit Universitas Terbuka.

[8] Purnomo, Setiawan Hari, Zulkieflimansyah, 2005, Manajemen Strategi, Jakarta, Penerbit Fakultas Ekonomi Universitas Indonesia.
[9] Sampurno, 2011, Manajemen Stratejik:Menciptakan Keunggulan Bersaing Yang Berkelanjutan, Cetakan kedua,

[10] Jogyakarta, Gadjah Mada University Press.

[11] Schuurman, Dimitri; Baccarne, Bastiaan; De Marez, Lieven, 2012, Smart Ideas for Smart Cities: Investigating

[12] Crowdsourcing for Generating and Selecting Ideas for ICT Innovation in a City Context, Journal of

[13] Theoritical and Applied Electronic Coomerce Research 7.3; 49-62.

[14] Suyanto M, 2007, Strategic Management: Global Most Admired Companies, Yogyakarta, Penerbit Andi.

[15] Yahya, Arief, 2013, Great Spirit Grand Strategy: Corporate Philosophy, Leadership Architecture, and

[16] Corporate Culture for Sustainable Growth, Jakarta, Penerbit PT. Gramedia.

[17] Department for Business, Innovation and Skills: Smart Cities, 2013, 1 Victoria Street London, Crown copyright.

[18] Strategic Plan for the City of London Canada 20150219, download, 11 November 2015. 